\title{
LETTER
}

\section{Intravenous magnesium in subarachnoid hemorrhage}

\author{
Wilson F Abdo*, Cornelia W Hoedemaekers and Johannes G van der Hoeven \\ See related research by Wong et al., http://ccforum.com/content/15/1/R52
}

We would like to offer some comments on the updated meta-analysis on intravenous magnesium sulphate for aneurysmal subarachnoid hemorrhage [1], which was conducted by Wong and colleagues and published in a recent issue of Critical Care.

First, the authors did not mention a (non-blinded) randomized placebo-controlled trial conducted by Akdemir and colleagues and published in 2009 [2]. Although this study would probably not pass Wong and colleagues' method of scrutiny, we believe that it should be mentioned alongside two other studies the authors described but did not include in the data analysis.

Second, the study by Westermaier and colleagues [3] should not be included in the data analysis. These authors, in contrast to those of the other included studies in which magnesium was used as an add-on therapy, did not use nimodipine in any of the included patients. Wong and colleagues exclude the study by Schmid-Elsaesser and colleagues [4] because nimodipine was not used in the magnesium group but omit doing the same for the study by Westermaier and colleagues.
Third, Figure 3 [1] shows that the number of control subjects in 'Veyna 2002' was 20. However, in that study, the outcome data in the control group were present for only 16 patients ( 4 of the 20 patients were withdrawn because study requirements were not met) [5]. Accordingly, the risk ratios in Figure 3 should be adjusted.

Fourth, given Wong and colleagues' definition of delayed cerebral ischemia, we wonder why the studies of Veyna and colleagues [5], Muroi and colleagues [6], and their own study in 2006 [7] were not included in Figure 1 [1]. In the study by Veyna and colleagues [5], the outcome measure 'clinical vasospasm' was defined as a 'new focal neurological deficit that could not be accounted for by other causes'. Although the time frame in which this was scored is not mentioned, this was during the patients' stay in the intensive care unit and therefore would be clinically relevant to include in Figure 1 [1]. The same applies to the outcome measures 'delayed ischemic neurological deficit' in the study by Muroi and colleagues [6] and 'symptomatic vasospasm' in their own study in 2006 [7].

\section{Authors' response}

George KC Wong and Wai S Poon

We thank Abdo and colleagues for their interest in our articles $[1,8]$ and for their comments. We would like to offer the following clarifications.

First, it is unfortunate that the article by Akdemir and colleagues [2] slipped through the established search methodology for the journals. Nevertheless, the authors' results on the lack of an effect of magnesium sulphate infusion on clinical outcome echoed the conclusion of our review.

*Correspondence: fabdo@ic.umcn.nl

Department of Critical Care Medicine, Radboud University Nijmegen Medical Center, Geert Grooteplein 10, PO Box 9101, 6500 HB Nijmegen, The Netherlands
Second, the study by Schmid-Elsaesser and colleagues [4] compared magnesium sulphate infusion with nimodipine, the latter of which has an established beneficial effect on aneurysmal subarachnoid hemorrhage. The study by Westermaier and colleagues [3] was trickier in mentioning how their cohort of patients employed nimodipine in the Discussion section but not in the Results section. Westermaier and colleagues mentioned that they did not seek an alternative route of administration for oral tablet forms of nimodipine for intubated patients but did not mention that they would omit the nimodipine oral tablets in good-grade patients. This actually is the policy in some neurosurgical centers. The nature of the comparison between magnesium sulphate infusion with placebo infusion is also different 


\begin{tabular}{|c|c|c|c|c|c|c|c|}
\hline \multirow[b]{2}{*}{ Stucty or Subgroup } & \multicolumn{2}{|c|}{ Magnesium } & \multicolumn{2}{|c|}{ Control } & \multirow[b]{2}{*}{ Weight } & \multirow{2}{*}{$\begin{array}{c}\text { Risk Ratio } \\
\text { M-H, Fixed, } 95 \% \mathrm{Cl}\end{array}$} & \multirow{2}{*}{$\begin{array}{c}\text { Risk Ratio } \\
\text { M-H, Fixed, 95\% Cl }\end{array}$} \\
\hline & Events & Total & Events & Total & & & \\
\hline Muroi 2008 & 22 & 31 & 17 & 27 & $15.3 \%$ & $1.13[0.78,1.63]$ & \\
\hline van den Bergh 2005 & 101 & 139 & 93 & 144 & $77.1 \%$ & $1.13[0.96,1.32]$ & \\
\hline Veyna 2002 & 13 & 20 & 8 & 16 & $7.5 \%$ & $1.30[0.72,2.34]$ & \\
\hline Total $(95 \% \mathrm{Cl})$ & & 190 & & 187 & $100.0 \%$ & $1.14[0.99,1.31]$ & 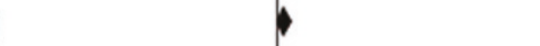 \\
\hline Total events & 136 & & 118 & & & & \\
\hline $\begin{array}{l}\text { Heterogeneity: } \mathrm{Chi}^{2}= \\
\text { Test for overall effect: }\end{array}$ & $\begin{array}{l}22, \mathrm{df}= \\
=1.80(\mathrm{~F}\end{array}$ & $\begin{array}{l}(P=0 . \\
=0.07)\end{array}$ & $90) ; 1^{2}=$ & & & & $\begin{array}{|cccc|} & 1 & 1 \\
0.01 & 0.1 & 1 & 10 \\
\text { Favours experimental } & \text { Favours control }\end{array}$ \\
\hline
\end{tabular}

Figure 1. Fixed-effects model of risk ratio for a favorable outcome at 3 months. A comparison between magnesium sulphate infusion and a placebo in patients with aneurysmal subarachnoid hemorrhage is shown. Cl, confidence interval; M-H, Mantel-Haenszel.

from that of Schmid-Elsaesser and colleagues [4]. Again, the omission of the data of Westermaier and colleagues did not alter the conclusion of the review.

Third, Veyna and colleagues [5] exposed a problem in the earlier study report format, in which numbers of patients were not mentioned in each step. Withdrawal could mean just the study medications, and the patients were assessed for intention-to-treat analysis. If the four control patients had been excluded, the result would have been the same (Figure 1) $[5,6,9]$.

Fourth, the new definition of delayed cerebral ischemia included the subsets of patients with asymptomatic cerebral infarction [10], which turned out to be an important prognostic factor and which earlier studies ignored. Lastly, we would like to emphasize that the detrimental effect of higher-achieved plasma magnesium concentrations further supported the results of the current meta-analysis [11].

\section{Competing interests}

The authors declare that they have no competing interests.

Published: 24 May 2011

\section{References}

1. Wong GK, Poon WS, Boet R, Chan MT, Gin T, Ng SC, Zee B: Intravenous magnesium sulphate for aneurysmal subarachnoid hemorrhage: an updated systemic review and meta-analysis. Crit Care 2011, 15:R52.

2. Akdemir H, Kulaksizogly O, Tucer B, Menku A, Postalci L, Gunaldi O: Magnesium sulfate therapy for cerebral vasospasm after aneurysmal subarachnoid hemorrhage. Neurosurg Q 2009, 19:35-39.

3. Westermaier T, Stetter C, Vince GH, Pham M, Tejon JP, Eriskat J, Kunze E, Matthies C, Ernestus RI, Solymosi L, Roosen K: Prophylactic intravenous magnesium sulfate for treatment of aneurysmal subarachnoid hemorrhage: a randomized placebo-controlled, clinical study. Crit Care Med 2010, 38:1284-1290.

4. Schmid-Elsaesser R, Kunz M, Zausinger S, Prueckner S, Briegel J, Steiger HJ: Intravenous magnesium versus nimodipine in the treatment of patients with aneurysmal subarachnoid hemorrhage: a randomized study. Neurosurgery 2006, 58:1054-1065.

5. Veyna RS, Seyfried D, Burke DG, Zimmerman C, Mlynarek M, Nichols V, Marrocco A, Thomas AJ, Mitsias PD: Magnesium sulphate therapy after aneurysmal subarachnoid hemorrhage. J Neurosurg 2002, 96:510-514.

6. Muroi C, Terzic A, Fortunati M, Yonekawa Y, Keller E: Magnesium sulphate in the management of patients with aneurysmal subarachnoid hemorrhage: a randomized, placebo-controlled, dose-adapted trial. Surg Neurol 2008, 69:33-39.

7. Wong GK, Chan MT, Boet R, Poon WS, Gin T: Intravenous magnesium sulfate after aneurysmal subarachnoid hemorrhage: a prospective randomized pilot study. J Neurosurg Anesthesiol 2006, 18:142-148.

8. Wong GK, Poon WS, Chan MT, Boet R, Gin T, Ng SC, Zee BC; IMASH Investigators: Intravenous magnesium sulphate after aneurysmal subarachnoid hemorrhage: a multi-center phase III study. Stroke 2010, 41:921-926.

9. van den Bergh WM, Algra A, van Kooten F, Dirven CM, van Gijn J, Vermeulen M, Rinkel GJ; MASH Study Group: Magnesium sulphate in aneurysmal subarachnoid hemorrhage. Stroke 2005, 36:1011-1015.

10. Vergouwen MD, Vermeulen M, van Gijn J, Rinkel GJ, Wijicks EF, Muizelaar JP, Mendelow AD, Juvela S, Yonas H, Terbrugge KG, Macdonald RL, Diringer MN, Broderick JP, Drier JP, Roos YB: Definition of delayed cerebral ischemia after aneurysmal subarachnoid hemorrhage as an outcome event in clinical trials and observation studies: proposal of a multidisciplinary research group. Stroke 2010, 41:2391-2395.

11. Wong GK, Poon WS, Chan MT, Boet R, Gin T, Ng SC, Zee BC: Plasma magnesium concentrations and clinical outcomes in aneurysmal subarachnoid hemorrhage patients: post-hoc analysis of Intravenous Magnesium Sulphate for Aneurysmal Subarachnoid Hemorrhage (IMASH) Trial. Stroke 2010, 41:1841-1844.

doi:10.1186/cc10221

Cite this article as: Abdo WF, et al.: Intravenous magnesium in subarachnoid hemorrhage. Critical Care 2011, 15:427. 